design of the EMS system is the most influential. The dynamic use of performance indicators to analyze, modify, and refine structural characteristics will optimize system design and enhance organizational capabilities for a successful disaster medical response.

Keywords: disaster; EMS; organization; system design Prebosp Disast Med 2002;17:s4-5.

\section{Establishing Health Epidemiology for Chemical Spills in Mining Industries Jinky Leilanie Lu}

Professor, Occupational Health Program, National Institutes of Health, University of the Philippines, Manila

Objectives: To look into health epidemiology of investigating and handling chemical spills in mining industries.

Methods: The research study was a preliminary study for a framework on how to investigate and handle chemical spills from a metallic mining industry in the Philippines. Consultations with experts from other disciplines such as sociology, epidemiology, occupational and environmental health, engineering, applied chemistry, and social work were done.

Chemical spills in the country from mining industries are not uncommon. When such emergencies arise, there is a need to develop a standard procedure on the proper investigation, gathering of data, and handling of the situation. The basic elements should include primarily the following: investigation of the workplace; investigation of the immediate environment, and health investigations among community dwellers, and establishing parameters of emergency management. Investigation of the workplace involves a detailed account of the industrial accident, the causes of leaks or spillage into the external environment such as the river system, looking into the breakdown of work process, machines, and other facilities. It also is necessary to establish the chemical composition and amount of use. Then, profiling of the external environment can be done for the ambient air, river site maps, and soil (whichever is affected). Samples of water and soil should be done on a scale and spatial basis to establish distance of affectation. Air sampling of chemical exposures shall provide data on concentrations. Then, affectation on livestock and people also must be investigated. This can be done by sampling nearby residents and getting some biologic samples from blood or urine, whichever is more efficient to establish biologic determinants. From such data gathering, the researcher can establish rating systems which are the most affected and serious areas/people and the consequent appropriate management.

Conclusion: A standard management procedure was developed on how to investigate chemical spills from mining industries to control and arrest the adverse effects of chemical spillage into the health, property, and livelihood of community dwellers.

Keywords: ambient air; biological monitoring; chemical spills; epidemiology; mining industry; monitoring

Prehosp Disast Med 2002;17:s5.

\section{Controlling Environmental Pollution Disaster from Industrial Emissions}

Maria Gilda Plata

Quality Systems and Pollution Control Officer, Industrial Safety and Health Services, The Philippines

Objectives: To identify control measures for a possible environmental pollution disaster from industrial emissions. The Philippine Environment and Natural Resources has identified industrial pollution as a major pollutant of the environment next to vehicle emissions. The industry as the target area uses solvents such as Ethyl Acetate (EAC), Methyl Ethyl Ketone (MEK), Ethanol, and Isopropyl Alcohol (IPA) for the printing and lamination of plastics. The consumption of solvents is categorized as high using as much as $40-60$ tons of mixed solvents. Therefore, there is a need to identify a control device to clean the air prior to emission into the external environment.

Methods: The study was conducted in a manufacturing industry with about 400 employees and in a highly populated community. Monitoring of exhaust emissions for various solvents was done using detector tubes, sampling pumps, and charcoal tubes.

Results: Ambient concentrations in the work area and stack emission concentrations indicated the following measurements which all were above the limit thresholds value (LTV) set by OSHA. Both workers and community dwellers were exposed to high concentrations of solvents that may cause diseases such as cancer and problems with reproductive health. Both adsorbent tubes were effective in reducing the concentrations of solvent fumes. The activated alumna was more effective for both MEK and IPA.

Conclusion: Environmental disaster from solvents in factories can be reduced by using adsorbents in the ducting system as an air control device.

Keywords: adsorbents; chemicals; ducting system; exhaust; industrial emission; pollution; solvents

Prehosp Disast Med 2002;17:s5.

\section{Disaster Surveillance Approaches for Technological Hazards in Semiconductor Industries Jonalyn Del Prado University of the Philippines, The Philippines}

The 21st Century has witnessed the growth of semiconductor industries in the Philippines as a response to the call of the government to invite more multi-national investments needed to stimulate the Philippine economy. As a result of this, semiconductor plants have been accommodated in export processing zones that focus on the backend processing of semiconductor manufacturing, particularly the soldering of microchips on frames. Other machineries brought to the country include washing and degreasing facilities for the microchips which emit acids such as hydrochloric and sulfuric acids. This study documented allergic reactions related to this exposure. Lead soldering also was associated with spontaneous abortion among the women, including some cases with that eventually may lead to the development of leukemia. The use of 